Palazzo et al. Studying catabolism of protein ADP-ribosylation

\title{
Studying catabolism of protein ADP-ribosylation
}

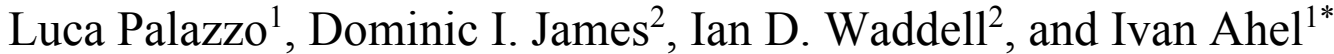

${ }^{1}$ Sir William Dunn School of Pathology, University of Oxford, Oxford. OX1 3RE, United Kingdom.

${ }^{2}$ Cancer Research UK Manchester Institute Drug Discovery Unit, University of Manchester, Manchester. M20 4BX, United Kingdom.

${ }^{*}$ Corresponding Author: ivan.ahel@path.ox.ac.uk

Running Head: Studying catabolism of protein ADP-ribosylation 
Palazzo et al. Studying catabolism of protein ADP-ribosylation

\title{
Studying catabolism of protein ADP-ribosylation
}

\section{Luca Palazzo' ${ }^{1}$, Dominic I. James ${ }^{2}$, Ian D. Waddell ${ }^{2}$, and Ivan Ahel ${ }^{1^{*}}$}

${ }^{1}$ Sir William Dunn School of Pathology, University of Oxford, Oxford. OX1 3RE, United Kingdom.

${ }^{2}$ Cancer Research UK Manchester Institute Drug Discovery Unit, University of Manchester, Manchester. M20 4BX, United Kingdom.

*Corresponding Author: ivan.ahel@path.ox.ac.uk

\begin{abstract}
Protein ADP-ribosylation is a conserved post-translational modification that regulates many major cellular functions, such as DNA repair, transcription, translation, signal transduction, stress response, cell division, aging and cell death. Protein ADP-Ribosyl Transferases catalyse the transfer of an ADPribose (ADPr) group from the $\beta$-Nicotinamide Adenine Dinucleotide ( $\beta$-NAD + ) cofactor onto a specific target protein with the subsequent release of nicotinamide. ADP-ribosylation leads to changes in protein structure, function, stability and localisation thus defining the appropriate cellular response. Signalling processes that are mediated by modifications need to be finely tuned and eventually silenced and one of the ways to achieve this is through the action of enzymes that remove (reverse) protein ADPribosylation in a timely fashion such as PARG, TARG1 and MACROD1. Here, we describe several basic methods used to study the enzymatic activity of de-ADP-ribosylating enzymes.
\end{abstract}

Key words: Poly(ADP-ribose) polymerase, ADP-ribosylation, PARG, Macrodomain, ADP-ribose, biochemical assay, hydrolases. 
Palazzo et al. Studying catabolism of protein ADP-ribosylation

\section{Introduction}

Protein ADP-ribosylation is a post-translational modification that regulates many major cellular functions, such as DNA damage response and repair, transcription, translation, signal transduction, stress response, cell division, aging and cell death $[1,2]$. Protein ADP-ribosylation is synthesised by several families of enzymes that can act as protein ADP-Ribosyl Transferases (ART), namely poly ADP-ribosyl polymerases (PARPs), ARTCs (cholera toxin-like transferases), and sirtuins [1]. All these enzymes can utilise nicotinamide adenine dinucleotide $\left(\mathrm{NAD}^{+}\right)$as a substrate to transfer ADP-ribose (ADPr) to target proteins. In response to an initial stimulus, the majority of ARTs can catalyse the addition of only one unit of ADPr (mADPr; MARylation) onto target proteins. However, several PARP family members such as PARP1, PARP2, and Tankyrases can add long chains of the repeating ADPribose units to their protein targets (polyADPr; pADPr; PARylation) (Figure 1) [1]. Due to its highly negative charge and size, ADP-ribosylation can strongly affect protein function, interactions, localization and stability $[1,2]$. During the regulation of cellular processes, protein ADP-ribosylation signalling needs to be tightly controlled and one way of achieving this is through the timely action of the enzymes that remove (reverse) ADP-ribosylation [3, 4]. PAR glycohydrolase (PARG) is the most characterized enzyme in humans for PAR hydrolysis, which specifically cleaves the ribose-ribose bonds between the ADPr subunits of the PAR chains [5, 6]. Another enzyme able to reverse protein PARylation is ADP-ribosylhydrolase 3 (ARH3) (Figure 1) [7]. However, these two enzymes are unable to process a single unit of ADPr attached to a protein [6, 7]. Indeed, terminal ADPr unit and MARylation directly linked to an acidic amino acid of the acceptor proteins can be removed by proteins, such as terminal ADPr protein glycohydrolase (TARG1), MacroD1 and MacroD2 [1, 8-10] (Figure 1). MARylation linked to arginine residues can be removed by ARH1 [11]. Recently, new classes of enzymes have been identified, capable of partially cleaving the ADP-riboylation producing the proteins carrying phosphoribosylated tags (such as NUDT16 and ENPP1 (Figure 1) [12, 13].

In this chapter, we describe four commonly used assays to study biochemical activity of enzymes involved in degradation of protein ADP-ribosylation. These assays include: assessment of hydrolytic activity of candidate recombinant enzymes by SDS PAGE using autoADP-ribosylated PARPs as substrates, both using immunodetection (Figure 2A) or autoradigraphy (Figure 2B), and analysis of the reaction products of hydrolases by thin layer chromatography (TLC). We also describe a method to measure glycohydrolase activity of human PARG in cells using an immunofluorescence technique. 


\section{Materials}

\section{1 autoADPribosylation of PARP1 and western blotting}

1. PARP Enzyme

2. $10 \times$ Activated DNA

3. 20 mM NAD (Note 1)

4. PARP Buffer 10X: $500 \mathrm{mM}$ Tris- $\mathrm{HCl} \mathrm{pH} 8.0,40 \mathrm{mM} \mathrm{MgCl}, 500 \mathrm{mM} \mathrm{NaCl}, 2 \mathrm{mM}$ DTT

5. PD SpinTrap G-25 (GE Healthcare) (Note 2)

6. 1 mM Olaparib (alternative names: AZD2281, KU0059436)

7. Recombinant PARG (Note 3)

8. Recombinant NUDT16 (Note 4)

9. Recombinant TARG1 (Note 5)

10. NuPAGE LDS Sample Buffer $(4 \times)$ (Life Technologies)

11. 2 -Mercaptoethanol $\geq 99.0 \%$

12. LDS sample buffer $4 \times$ containing 2-Mercaptoethanol $(1.144 \mathrm{M})$

13. NuPAGE 4-12\% Bis-Tris Gel (Life Technologies)

14. NuPAGE MOPS SDS Running Buffer (20×) (Life Technologies)

15. Protein pre-stained standard

16. Trans-Blot ${ }^{\circledR}$ Turbo $^{\mathrm{TM}}$ Transfer System (Biorad)

17. Trans-Blot ${ }^{\circledR}$ Turbo ${ }^{\mathrm{TM}}$ Nitrocellulose Transfer Packs (Biorad)

18. Nonfat dry milk powder (Nonfat Marvel Dried Skimmed Milk, NFDM)

19. Rabbit Anti-PAR Polyclonal Antibody (Trevigen)

20. Rabbit Anti-PARP1 ab6079 (Abcam)

21. Tween-20

22. PBS $1 \times /$ Tween-20 $0.1 \%$ (PBS-T)

23. PBS $1 \times /$ Tween-20 0.1\% containing 5\% NFDM (PBS-TM)

24. Polyclonal Swine Anti-Rabbit Immunoglobulins/HRP

25. ECL Western Blotting Substrate

26. Amersham Hyperfilm ECL (GE Healthcare)

\section{2 autoADPribosylation of PARP1 in presence of radiolabelled NAD ${ }^{+}$}

1. NAD, [32P]- $800 \mathrm{Ci} / \mathrm{mmol} 5 \mathrm{mCi} / \mathrm{ml}$ (PerkinElmer)

2. Fixing solution: $10 \%(\mathrm{v} / \mathrm{v})$ Acetic Acid, $10 \%(\mathrm{v} / \mathrm{v})$ Methanol

3. Whatman ${ }^{\mathrm{TM}} 3 \mathrm{MM}$ Chr Chromatography Paper

4. Gel Dryer 
5. BIOMAX Maximum Sensitivity Film (Kodak)

\subsection{Thin Layer Chromatography (TLC)}

1. POLYGRAM CEL 300 PEI (MACHEREY-NAGEL)

2. TLC mobile phase: $0.15 \mathrm{M}$ Formic Acid, $0.15 \mathrm{M}$ Lithium Chloride (Note 6)

3. TLC developing tank

\section{4 autoADPribosylation of PARP1-E988Q mutant}

1. Recombinant PARP1-E988Q (Note 7)

\subsection{Measurement of glycohydrolase activity of human PARG in cells}

2.5.1 Cell culture and plating:

1. HeLa cells (CCL-2 from ATCC)

2. Cell culture media RPMI - 1640

3. Fetal bovine serum (FBS)

4. L-Glutamine

5. $75 \mathrm{~cm}^{2}$ cell Culture flasks

6. BD Falcon $40 \mu \mathrm{M}$ Cell Strainer

7. ViaFlow Assist

8. Black 384 well plates (Greiner)

9. Gloves

10. Falcon $50 \mathrm{~mL}$ tubes

11. Merck Millipore Muse cell counter or any other cell counter

12. TrypLE Express

2.5.2 Dosing cells:

1. Methyl methanesulfonate (MMS) $(1.3 \mathrm{~g} / \mathrm{ml})$.

2. PARG inhibitor

3. DMSO

4. Labcyte Echo source plates

5. Labcyte Echo 555

\subsubsection{Staining cells:}

1. Phosphate buffered saline (PBS)

2. Methanol - HPLC grade

3. Triton $\mathrm{X}-100$

4. Tween 20 
Palazzo et al. Studying catabolism of protein ADP-ribosylation

5. Anti-PAR mouse monoclonal antibody (10H) (Calbiochem AM80)

6. Alexa Fluor ${ }^{\circledR} 488$ goat anti mouse $\operatorname{IgG}(\mathrm{H}+\mathrm{L})$

7. Hoechst 33342

8. Nunc aluminium seal tape for $96-$-well plates

2.5.4 Capturing images:

1. Thermo Scientific ${ }^{\mathrm{TM}}$ CellInsight ${ }^{\mathrm{TM}}$ platform for high-content analysis 
Palazzo et al. Studying catabolism of protein ADP-ribosylation

\section{Methods}

\section{1. autoADPribosylation of PARP1 and western blotting}

\subsubsection{Activation of PARP1 and automodification}

1. Preparation of fresh PARP buffer 10×.

2. Calculate $10 \mu \mathrm{l}$ of reaction for each experimental point (Note 8).

3. Once determined the final volume of master mix, dilute PARP buffer $10 \times$ to $1 \times$ final, add $\mathrm{NAD}^{+}$to $200 \mu \mathrm{M}$ final concentration, activated DNA $10 \times$ to $1 \times$ final, $1 \mu \mathrm{L}$ of PARP1 (10 units $/ \mu \mathrm{L}$ ) every $50 \mu \mathrm{L}$ of reaction, and add nuclease free water to the final volume.

4. Incubate the reaction 20 minutes at room temperature.

5. Add $1 \mu \mathrm{M}$ olaparib (KU0059436) to inhibit PARP1

\subsubsection{Desalting of automodified PARP1 mix (Optional)}

1. Depending on the type of experiment, a desalting step may be required to remove excess of unreacted NAD ${ }^{+}$. For this step, we use PD SpinTrap G-25 columns. They contain Sephadex G-25 Medium, which allows rapid group separation of high molecular weight substances from low molecular weight substances. Therefore, small molecules such as salts, unincorporated $\mathrm{NAD}^{+}$, DNA fragments, and other impurities are efficiently separated from the high molecular weight substances of interest.

2. A number of three G-25 are suggested to enrich in highly modified PARP1. Thus, three G25 columns were equilibrated five times into the desired buffer, in according to manufacture protocol.

3. Pass the mix containing automodified PARP1 through three different equilibrated G25 columns. The final flow through is then ready for downstream experiments.

\subsubsection{PARP1 as substrate to test hydrolytic activity of candidate enzymes (Note 9)}

1. Aliquot $10 \mu \mathrm{L}$ of PARP1 mix in clean tubes for each experimental point, including a negative control.

2. To test hydrolytic activity of candidate enzymes, consider a final volume of reaction of $15 \mu \mathrm{L}$ (Note 10).

3. Add desired concentrations of hydrolytic enzymes and buffer to $15 \mu \mathrm{L}$.

4. Incubate reaction at desired temperature and time (Note 11).

5. Stop reaction by adding $4 \mu \mathrm{L}$ of LDS sample buffer $(4 \times)$ containing 2 -Mercaptoethanol and mix properly.

6. Boil sample 2 minutes at $90^{\circ} \mathrm{C}$.

7. Centrifuge samples at maximum speed for 30 seconds. 
8. Load in duplicate $8 \mu \mathrm{L}$ of each sample in two separate SDS-PAGE gels. One will be blotted against PAR and the second one against PARP1 (Note 12) (Figure 3A and B).

9. Run samples on SDS-PAGE gels at $180 \mathrm{~V}$ for $\sim 1$ hour. Stop the gel when the migration dye front has arrived to the end of the gel length.

10. Transfer proteins from gels to nitrocellulose membranes. We use Trans-Blot ${ }^{\circledR}$ Turbo $^{\mathrm{TM}}$ Transfer System, using Standard programme (25V, 1.0 A, 30 minutes) setting transfer.

11. Wash the nitrocellulose membranes in PBS-T and incubate with PBS-TM at room temperature for 1 hour with gentle agitation.

12. Wash membranes with PBS-T twice for 5 minutes.

13. Incubate one nitrocellulose membrane with anti-PAR (1:2000), and the second one with anti-PARP1 (1:1000) diluted in PBS-TM at room temperature for 1 hour.

14. Discard and regain the primary antibodies and wash membranes twice in PBS.

15. Wash membranes with PBS-T twice for 5 minutes.

16. Incubate nitrocellulose membrane with polyclonal swine anti-rabbit immunoglobulins/HRP diluted 1:3000 in PBS-TM at room temperature for 1 hour.

17. Wash membranes twice in PBS.

18. Wash membranes with PBS-T twice for 5 minutes.

19. Wash membranes twice in PBS.

20. Perform western blot chemiluminescent reactions.

21. Develop western blots.

\section{2 autoADPribosylation of PARP1 in presence of radiolabelled $\mathrm{NAD}^{+}$}

\subsubsection{Activation of PARP1 wild type and automodification using radio-labelled NAD}

1. Preparation of fresh PARP buffer 10×

2. Calculate $10 \mu \mathrm{l}$ of reaction for each experimental point (Note 8).

3. Once determined the final volume of master mix, dilute PARP buffer $10 \times$ to $1 \times$ final, add cold $\mathrm{NAD}^{+}$to $2 \mu \mathrm{M}$ final concentration, activated DNA $10 \times$ to $1 \times$ final, $0.5 \mu \mathrm{Ci}$ $[32 \mathrm{P}]-\mathrm{NAD}^{+}$, and nuclease free water to the final volume. Mix by pipetting.

4. Add $1 \mu \mathrm{L}$ of PARP1 (10 units $/ \mu \mathrm{L}$ ) every $50 \mu \mathrm{L}$ of reaction.

5. Incubate the reaction 20 minutes at room temperature.

6. Add $1 \mu \mathrm{M}$ olaparib (KU0059436) to inhibit PARP1.

\subsubsection{Desalting of automodified PARP1 mix (Optional)}

1. Perform desalting as described in paragraph 3.1.2. If desired to perform TLC as a downstream approach, this step is essential to get a clean chromatography pattern. 
3.2.3 Radiolabelled PARP1 as substrate to test hydrolytic activity of candidate enzymes (Note 9)

1. Aliquot $10 \mu \mathrm{L}$ of PARP1 mix in clean tubes for each experimental point, including a negative control.

2. To test hydrolytic activity of candidate enzymes, consider a final volume of reaction of $15 \mu \mathrm{L}$ (Note 10).

3. Add desired concentrations of hydrolytic enzymes and buffer to $15 \mu \mathrm{L}$.

4. Incubate reaction at desired temperature and time.

5. If desired to perform TLC as downstream assay, save $2 \mu \mathrm{L}$ of reaction in a clean tube.

6. Stop reaction by adding $4 \mu \mathrm{L}$ of LDS sample buffer $(4 \times)$ containing 2 Mercaptoethanol and mix properly.

7. Boil sample 2 minutes at $90^{\circ} \mathrm{C}$.

8. Centrifuge samples at maximum speed for 30 seconds.

9. Load samples and run on SDS-PAGE gels at $180 \mathrm{~V}$ for $\sim 1$ hour. Stop the gel when the migration dye front has arrived to the end of the gel length.

10. Wash gel twice in water for 5 minutes at room temperature with gentle agitation.

11. Add fixing solution to the gel and incubate it for at least 30 minutes.

12. Discard fixing solution and wash the gel in water with frequent water changes for at least 1 hour.

13. Place gel on 3 MMchromatography paper and dry it using gel dryer.

14. Expose the gel using normal ECL film or high sensitivity X-Ray films (Figure 4A).

\subsection{Thin Layer Chromatography (TLC)}

Separation of radiolabelled small compounds on TLC plate.

1. Prepare one POLYGRAM CEL 300 PEI TLC plate.

2. Use a ruler to define the input line. The input line has to be at $1.6 \mathrm{~cm}$ from the bottom of plate.

3. Using a thin pencil, mark on the input line the loading points. Every point has to be 1 $\mathrm{cm}$ spaced from the others.

4. Spot $1 \mu \mathrm{L}$ of each sample on loading point.

5. Let the drop dry.

6. Decant the TLC mobile phase into the TLC developing tank and gently place TLC plate inner.

7. Cover the tank to avoid evaporation. 
Palazzo et al. Studying catabolism of protein ADP-ribosylation

8. When the migration arrives at $1 \mathrm{~cm}$ from the top of TLC plate, gently remove the plate from the tank and air dry it (Note 13).

9. Expose the gel using normal ECL film or high sensitivity X-Ray films (Figure 4B).

\section{4 autoADPribosylation of PARP1-E988Q mutant}

\subsubsection{Activation of PARP1-E988Q and automodification}

1. Preparation of fresh PARP buffer $10 \times$

2. Calculate $10 \mu \mathrm{L}$ of reaction for each experimental point (Note 8).

3. Once determined the final volume of master mix, dilute PARP buffer $10 \times$ to $1 \times$ final, add cold $\mathrm{NAD}^{+}$to $2 \mu \mathrm{M}$ final concentration, activated DNA $10 \times$ to $1 \times$ final, $0.5 \mu \mathrm{Ci}$ $[32 \mathrm{P}]-\mathrm{NAD}+$, and nuclease free water to the final volume. Mix by pipetting.

\section{Add $1 \mu \mathrm{M}$ of PARP1-E988Q (Note 7).}

5. Incubate the reaction 20 minutes at room temperature.

6. Add $1 \mu \mathrm{M}$ olaparib (KU0059436) to inhibit PARP1.

\subsubsection{PARP1-E988Q as substrate to test hydrolytic activity of candidate enzymes (Note 9)}

1. Aliquot $10 \mu \mathrm{L}$ of PARP1-E988Q mix in clean tubes for each experimental point, including a negative control.

2. To test hydrolytic activity of candidate enzymes, consider a final volume of reaction of $15 \mu \mathrm{L}$ (Note 10).

3. Add desired concentrations of hydrolytic enzymes and buffer to $15 \mu \mathrm{L}$. In Figure 5, we probed NUDT16 (Note 4) and TARG1 (Note 5).

4. Incubate reaction at desired temperature and time.

5. Stop reaction by adding $4 \mu \mathrm{L}$ of LDS sample buffer $(4 \times)$ containing 2Mercaptoethanol and mix properly.

6. Boil sample for 2 minutes at $90^{\circ} \mathrm{C}$.

7. Centrifuge samples at maximum speed for 30 seconds.

8. Load samples and run on SDS-PAGE gels at $180 \mathrm{~V}$ for $\sim 1$ hour. Stop the gel when the migration dye front has arrived to the end of the gel length.

9. Wash gel twice in water for 5 minutes at room temperature with gentle agitation.

10. Add fixing solution to the gel and incubate it for at least 30 minutes.

11. Discard fixing solution and wash the gel in water with frequent water changes for at least 1 hour.

12. Place gel on $3 \mathrm{MM}$ chromatography paper and dry it using a gel dryer.

13. Expose the gel using normal ECL film or high sensitivity X-Ray films (Figure 5). 


\subsection{Measurement of glycohydrolase activity of human PARG in cells}

\subsubsection{Cell preparation}

1. Make complete media by adding $50 \mathrm{~mL}$ FBS and $5 \mathrm{~mL}$ glutamine to RPMI 1640 .

2. Thaw Hela cells into media according to ATCC instructions

3. Maintain in culture in a T75 for two weeks and passage cells 2-3 times and do not let them become fully confluent (Note 14).

4. When ready prepare cells for assay.

5. Aspirate media from flask and add $20 \mathrm{~mL}$ PBS to monolayer. Gently swirl PBS and then aspirate.

6. Add $2.5 \mathrm{~mL}$ TrypLE cell dissociation liquid and ensure that it covers all cells by tipping flask. Aspirate all but $0.5-1 \mathrm{~mL}$ TrypLE and return flask to incubator for 4 minutes.

7. Remove flask from incubator and check that cells have rounded up then tap gently to detach from the bottom of flask

8. Add $20 \mathrm{~mL}$ complete media and pipette up and down three times before passing through a $40 \mu \mathrm{M}$ strainer in a $50 \mathrm{~mL}$ tube. Count cells (using two different samples from cell population - see Note $\mathbf{1 5}$ ).

9. Dilute cells to $4 \times 104$ cells $/ \mathrm{mL}$ and plate $30 \mu \mathrm{L}$ in each well of a $384-w e l l$ plate and incubate cells overnight at $37^{\circ} \mathrm{C}, 5 \% \mathrm{CO} 2$ (Note 16)

10 . Visually check cells using an inverted microscope to ensure equal distribution.

\subsubsection{Dosing cells}

The Echo 555 is an instrument that uses tipless, non-contact, acoustic fluid transfer for dispensing compounds. Using acoustic transfer eliminates the potential for samples or compounds to adhere to tips and helps to improve data quality. Compounds are typically pipetted into a low-dead volume (LDV) source plate and are fired using acoustic technology into an inverted plate (see Note 17). This should not be attempted unless the user has been thoroughly trained.

\subsubsection{Dose cells with compound}

1. Design dosing regimen using Echo Dose Response software (Note 18) and add trial compounds, PARG inhibitor (PDD00017273) and DMSO to the source plate. Spin the source plate at $150 \mathrm{~g}$ for 1 minute.

2. Spin the destination plate (containing the cells) at $1000 \mathrm{rpm}(164 \mathrm{~g})$ for $1 \mathrm{~min}$ (see Note 19) and use the Echo to dispense test compounds.

3. Incubate cells for $1 \mathrm{hr}$ at $37^{\circ} \mathrm{C}, 5 \% \mathrm{CO} 2$. 
1. Prepare MMS: To $63 \mu \mathrm{L}$ DMSO add $15 \mu \mathrm{L}$ MMS from commercial stock. This gives a secondary stock of $250 \mathrm{mg} / \mathrm{mL}$. Further dilute this using DMSO to $50 \mu \mathrm{g} / \mathrm{mL}$. Add $50 \mu \mathrm{g} / \mathrm{mL}$ MMS or DMSO to the source plate as appropriate and spin the source plate at $150 \mathrm{~g}$ for 1 minute.

2. Spin destination plate (containing cells) again at $1000 \mathrm{rpm}$ (164 g) for $1 \mathrm{~min}$

3. Use the Echo to dispense $30 \mathrm{~nL}$ MMS or DMSO into a 384-well plate (Note 18).

4. Check Echo firing report for compounds and MMS

5. Incubate cells for exactly $1 \mathrm{hr}$ at $37^{\circ} \mathrm{C}, 5 \% \mathrm{CO} 2$ (Note 20).

\subsubsection{Staining cells}

1. After incubation with MMS, fix cells: Tip/flick off media into a large bowl/tray and immediately add $50 \mu \mathrm{L} /$ well of ice-cold $95 \%$ methanol/PBS and incubate for 15 mins at $-20^{\circ} \mathrm{C}$.

2. Tip/flick off media/fixative and wash plates by adding $50 \mu \mathrm{L} /$ well PBS. This can be done manually or by using an automated device (Notes $21-\mathbf{2 3}$ ).

3. Tip/flick off PBS and permeabilise cells by adding $50 \mu \mathrm{L} /$ well of $0.1 \%$ Triton X-100 in PBS and incubate for 20 mins at RT.

4. Meanwhile prepare primary antibody stain by diluting anti-PAR mouse monoclonal antibody $(10 \mathrm{H})$ at $1 / 4000$ in $5 \%$ FBS in PBS $+0.05 \%$ Tween 20 . Calculate approximately $8 \mathrm{~mL}$ per plate (including overage).

5. Tip/flick off PBS/Triton and wash plates once by adding $50 \mu \mathrm{L} /$ well PBS.

6. Tip/flick off PBS and stain cells by adding $20 \mu \mathrm{L} /$ well of primary antibody and incubate overnight at $4^{\circ} \mathrm{C}$

7. Prepare secondary antibody stain by diluting Alexa Fluor ${ }^{\circledR} 488$ goat anti mouse IgG $(\mathrm{H}+\mathrm{L}))$ at $1 / 1000$ and Hoechst at 1:500 in 5\% FBS in PBS $+0.05 \%$ Tween 20 .

8. Using same technique as before wash plates three times with $50 \mu \mathrm{L} /$ well PBS.

9. Add $20 \mu \mathrm{L} /$ well of secondary antibody and incubate for $1 \mathrm{hr}$ at RT.

10. Wash plates three times with $50 \mu \mathrm{L} /$ well PBS.

11. Add plate seal and read plates on Cell Insight or another similar high content screening system.

\subsubsection{Data analysis using Cell Insight}

1. Load Cellomics Scan software.

2. Click Load/Unload plate and insert plate into the machine. Ensure A1 is in the correct orientation.

3. Change the protocol to compartmental analysis and select the 10x objective. 
4. Select two wells dosed at $30 \mu \mathrm{M}$ with PARG inhibitor and MMS (positive control) and two wells dosed with PARG inhibitor alone. Select Channel 1 and click Autofocus. Click Channel 2 and then Acquire Image. Select 4 on the contrast setting. The image will be automatically saved.

5. Go to Group Configuration window to load the images. Work through the following:

6. Look at Primary Object Identification Ch1 and check that the nuclei have been correctly identified.

7. Look at Primary Object Validation Ch1 and check that the correct nuclei have been validated.

8. Look at Spot identification $\mathrm{Ch} 2$ and check that spots are observed in the nuclei of the max wells. Set the threshold low enough that some signal is detected in your PARG alone dosed cells.

9. Look at the statistics for the CircSpotTotalIntensity and check the values for positive control and PARG alone dosed cells. Save the protocol.

10. Select the area of the plate you want to scan and click to scan the plate.

11. After the scan has completed, load the Cellomics View software. Select the plate from the list and report the following: Valid object count, Mean object area, Mean circspot total intensity $\mathrm{Ch} 2$.

12. Export the data to Excel and analyse in an appropriate software to calculate $\mathrm{IC}_{50}$ values (Note 24) 
Palazzo et al. Studying catabolism of protein ADP-ribosylation

\section{Notes}

1. Store at $-20^{\circ} \mathrm{C}$. Avoid freeze and thaw cycles.

2. PD SpinTrap G-25 desalting columns can be used to get rid of small compounds present into the PARP reaction of automodification, such as unreacted $\mathrm{NAD}^{+}$and DNA that can interfere with downstream enzymatic reactions.

3. Human recombinant PARG was expressed and purified as previously described in ref. [14].

4. NUDT16 was expressed and purified as previously described [12].

5. TARG1 was expressed and purified as previously described in ref. [8].

6. Always prepare fresh. First prepare $3 \mathrm{M}$ Lithium Chloride $(\mathrm{LiCl})$ solution and then prepare solution containing $10 \mathrm{~mL}$ of $3 \mathrm{M} \mathrm{LiCl}$ and $1.13 \mathrm{~mL}$ Formic Acid in water, $200 \mathrm{~mL}$ final volume.

7. pET28a PARP1-E988Q was expressed from and purified as previously described for wildtype PARP in ref. [15].

8. In order to avoid volume loss because of pipetting errors, always consider to prepare an activated PARP1 mix at least one sample (10 $\mu$ l reaction for each sample) in excess to the effective number of experimental points.

9. Some hydrolytic enzymes require divalent cations. For example, NUDT16, ARH1 and ARH3 require $\mathrm{MgCl}_{2}$. In this case, complementation in PARP1 master mix is necessary [12].

10. Final volume has to be decided by the experimenter depending on the starting concentration of recombinant hydrolytic enzymes to test. $15 \mu$ final volume is an example in which 10 $\mu 1$ are represented by the substrate (PARP1 mix) and a maximum of $5 \mu 1$ are available to treat ADP-ribosylated protein with desired concentrations of hydrolytic enzymes.

11. Incubation temperature and time depends on the efficiency of enzymes that have to be tested. PARG completely hydrolyses PARylate PARP1 at room temperature in 30 minutes. If nothing is known about the enzymes to be tested, incubate at $30^{\circ} \mathrm{C}$ for at least 3 hours.

12. Depending on the number of samples, we recommend to load the two set of samples into the same gel separated by a lane containing protein standard.

13. A fan heater can be used to quickly dry the TLC plate.

14. We have found that cells that have been in culture for less than two weeks or for more than 10 weeks tend to have greater variability (see James et al, F1000Research)

15. Although there are many ways to count cells we find the most reliable for single cell populations is to use the Cell Viability stain on Merck Millipore Muse cell counter and count 5000 cells.

16. Although this can be achieved manually using an appropriate multichannel pipette we find that using and an automated method (Viaflow Assist) gives more consistent results. 
17. The amount of media in the target or destination plate has to be demonstrated empirically. The plate is inverted in order to be dosed and then moves briskly whilst being dosed; too much media in each well will result in the media falling out of the well. Other fluid transfer instruments could be suitable but keep the percentage of DMSO added to the cells at less than $0.3 \%$.

18. We use the Echo Dose Response software to dispense compounds into 304 wells of a 384 well plate - that is, all wells apart from the outer wells which are often more variable due to edge effects. The plate is dosed so that seven compounds are dosed with a ten point dose response (3-fold dilutions from $30 \mu \mathrm{M}$ to $0.001 \mu \mathrm{M}$ ) in duplicate in the top half of the plate and the same seven compounds are dosed in duplicate in the bottom half of the plate. This then allows the compounds to be dosed with single dose of MMS (or DMSO).

19. The wells in a 384-well plate are cuboid and we suspect that the vertices will draw media up over time and disrupt the surface tension.

20. It is critical that each plate of cells is incubated for exactly the same amount of time with compound and MMS.

21. We use the Biotek Elx 405 Select CW plate washer if more than three plates are being stained at any one time. This minimises repetitive strain injury and ensures greater consistency of washing between plates.

22. After fixation and washing the plate containing the cells can be stored at $4{ }^{\circ} \mathrm{C}$.

23. This assay should be run twice in the same week on cells with the same passage number. This can be achieved by splitting cells at different densities on the week previous to the assay. When carrying out this protocol twice, the first run can be fixed and the plates left with PBS at $4^{\circ} \mathrm{C}$ after step 2 (staining cells).

24. Note that the assay uses MMS at a final concentration of $50 \mu \mathrm{g} / \mathrm{mL}$. If $\mathrm{EC}_{50} \mathrm{~s}$ shift, considering changing batch of MMS. 
Palazzo et al. Studying catabolism of protein ADP-ribosylation

\section{Acknowledgement}

This work was supported by the Wellcome Trust (grant number 101794), the European Research Council (grant number 281739) and by Cancer Research UK (grant numbers C480/A1141,C5759/A17098 and C35050/A22284).

\section{References}

1. Barkauskaite E, Jankevicius G, Ahel I (2015) Structures and Mechanisms of Enzymes Employed in the Synthesis and Degradation of PARP-Dependent Protein ADP-Ribosylation. Mol Cell 58:935-46

2. Bai P (2015) Biology of Poly(ADP-Ribose) Polymerases: The Factotums of Cell Maintenance. Mol Cell 58:947-58

3. Barkauskaite E, Jankevicius G, Ladurner AG, Ahel I, Timinszky G (2013) The recognition and removal of cellular poly(ADP-ribose) signals. FEBS J 280:3491-3507

4. Alvarez-Gonzales R, Althaus FR (1989) Poly(ADP-ribose) catabolism in mammalian cells exposed to DNA-damaging agents. Mutat Res 218:67-74

5. Lin W, Amé JC, Aboul-Ela N, Jacobson EL, Jacobson MK (1997) Isolation and characterization of the cDNA encoding bovine poly(ADP-ribose) glycohydrolase. J Biol Chem 272:11895-11901

6. Slade D, Dunstan M, Barkauskaite E, Weston R, Lafite P, Dixon N, Ahel M, Leys D, Ahel I (2011) The structure and catalytic mechanism of a poly(ADP-ribose) glycohydrolase. Nature 477:616-620

7. Oka S, Kato J \& Moss J (2006) Identification and characterization of a mammalian 39-kDa poly(ADP-ribose) glycohydrolase. J Biol Chem 281, 705-713

8. Sharifi R, Morra R, Appel CD, Tallis M, Chioza B, Jankevicius G, Simpson MA, Matic I, Ozkan E, Golia B, et al. (2013) Deficiency of terminal ADP-ribose protein glycohydrolase TARG1/C6orf130 in neurodegenerative disease. EMBO J 32:1225-1237

9. Rosenthal F, Feijs KL, Frugier E, Bonalli M, Forst AH, Imhof R, Winkler HC, Fischer D, Caflisch A, Hassa PO, Lüscher B, Hottiger MO (2013) Macrodomain-containing proteins are new mono-ADP-ribosylhydrolases. Nat Struct Mol Biol 20:502-507

10. Jankevicius G, Hassler M, Golia B, Rybin V, Zacharias M, Timinszky G, Ladurner AG (2013) A family of macrodomain proteins reverses cellular mono-ADP-ribosylation. Nat Struct Mol Biol 20:508-514

11. Kato J, Zhu J, Liu C, Moss J (2007) Enhanced sensitivity to cholera toxin in ADPribosylarginine hydrolase-deficient mice. Mol Cell Biol 27:5534-5543 
Palazzo et al. Studying catabolism of protein ADP-ribosylation

12. Palazzo L, Thomas B, Jemth AS, Colby T, Leidecker O, Feijs KL, Zaja R, Loseva, O, Puigvert JC, Matic I, Helleday T, Ahel I (2015) Processing of protein ADP-ribosylation by Nudix hydrolases. Biochem J 468:293-301

13. Palazzo L, Daniels CM, Nettleship JE, Rahman N, McPherson RL, Ong SE, Kato K, Nureki O, Leung AK, Ahel I. (2016) ENPP1 processes protein ADP-ribosylation in vitro. FEBS J doi: $10.1111 /$ febs. 13811 .

14. Lambrecht MJ, Brichacek M, Barkauskaite E, Ariza A, Ahel I, Hergenrother PJ (2015) Synthesis of dimeric ADP-ribose and its structure with human poly(ADP-ribose) glycohydrolase. J Am Chem Soc 137:3558-3564.

15. Langelier MF1, Planck JL, Servent KM, Pascal JM (2011) Purification of human PARP-1 and PARP-1 domains from Escherichia coli for structural and biochemical analysis. Methods Mol Biol 780:209-226.

\section{Figure Legends}

Figure 1. Cycle of protein ADP ribosylation.

Figure 2. Schematic illustration of some of the assays described in this chapter. A. PARP1 recombinant protein is activated in vitro in presence of DNA and $\mathrm{NAD}^{+}$. PARylated PARP1 is afterwards used as substrate to test hydrolytic activity of protein of interest. Read out is a western blot using anti-PAR antibody. If enzyme of interest is hydrolysing protein PARylation, there will be no antibody recognition. B. PARP1 recombinant protein is activated in vitro in presence of DNA and a mix of cold $\mathrm{NAD}^{+}$and radiolabelled $\mathrm{NAD}^{+}$. In this case, read out is an autoradiography. TLC can be used to characterize chemical by-products of enzymatic reaction.

Figure 3. AutoADP-ribosylation of PARP1 and analysis of pADPr hydrolytic activity by western blot.

Figure 4. AutoADP-ribosylation of PARP1 in presence of radiolabelled $\mathrm{NAD}^{+}$and analysis of pADPr hydrolytic activity by autoradiography and TLC. A. PARP1 was automodified as described and used as substrate for NUDT16 $(5 \mu \mathrm{M})$ and PARG $(1 \mu \mathrm{M})$. Samples were fractionated on SDS-PAGE as discussed in the relative paragraph and autoradiography shown in figure. B. $1 \mu$ of same samples shown in Fig 4A were loaded on TLC plate. PARylated PARP1 was not able to move from the loading point. NUDT16 mainly released phosphoribose-AMP (PRAMP), PARG releases units of ADPr.

Figure 5. AutoADP-ribosylation of PARP1-E988Q mutant and analysis of mADPr hydrolytic activity by autoradiography. PARP1-E988Q was used as substrate for hydrolytic activity of TARG1 $(1 \mu \mathrm{M})$ and NUDT16 $(5 \mu \mathrm{M})$. Samples were fractionated on SDS-PAGE as discussed in the relative paragraph and the autoradiography shown in figure. 

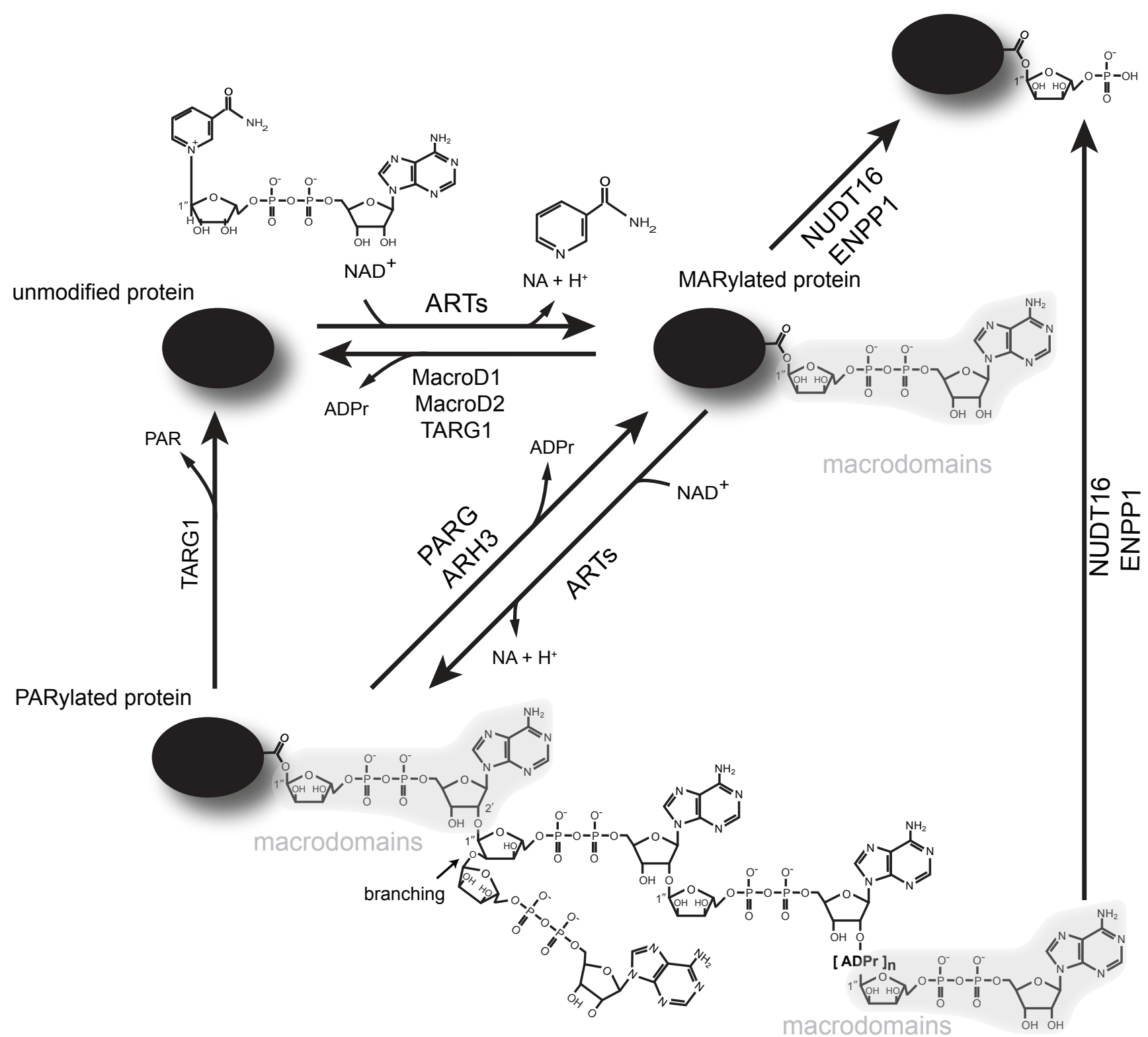

macrodomains
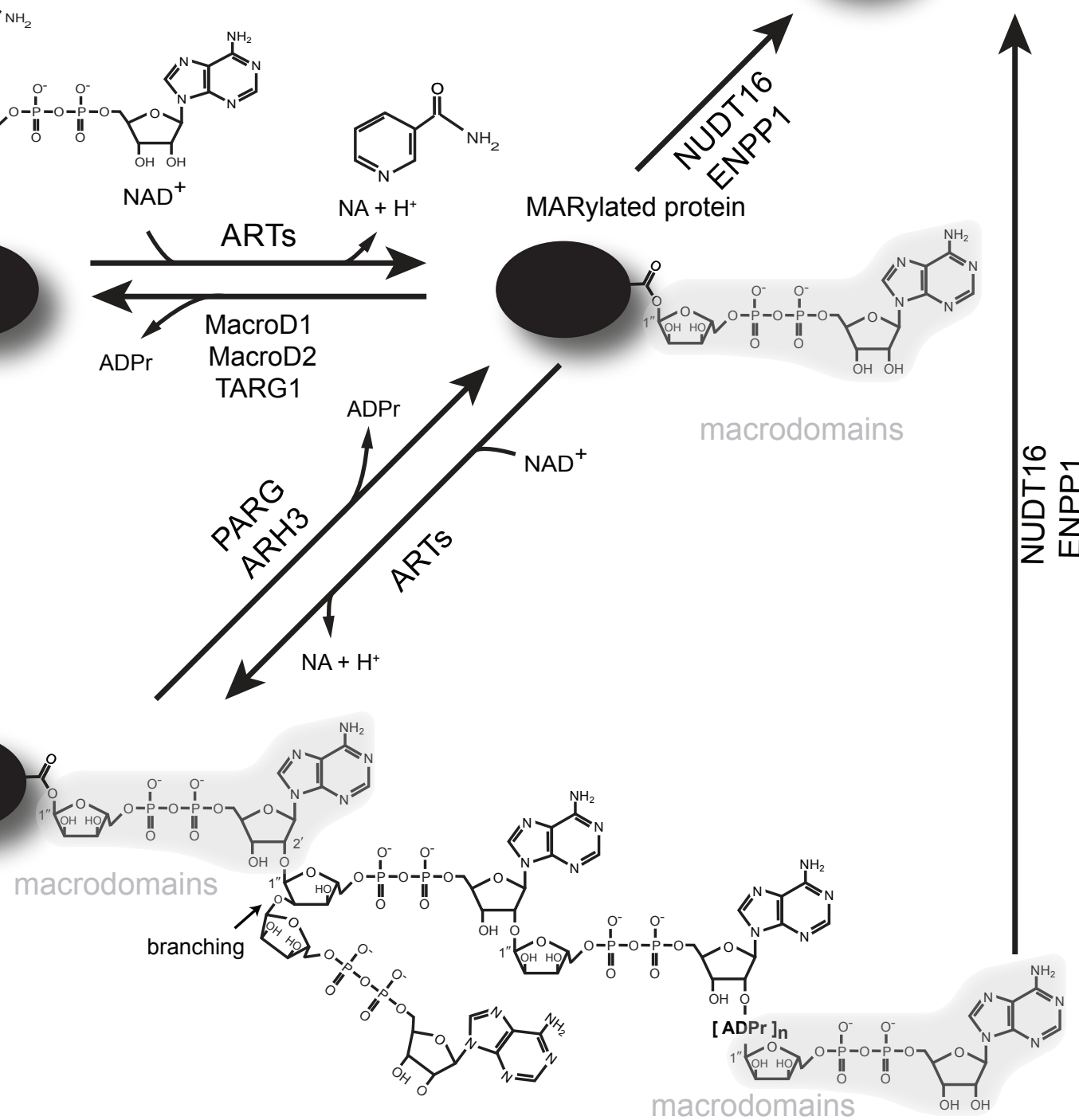

MARylated protein

PARylated protein 
Figure 2

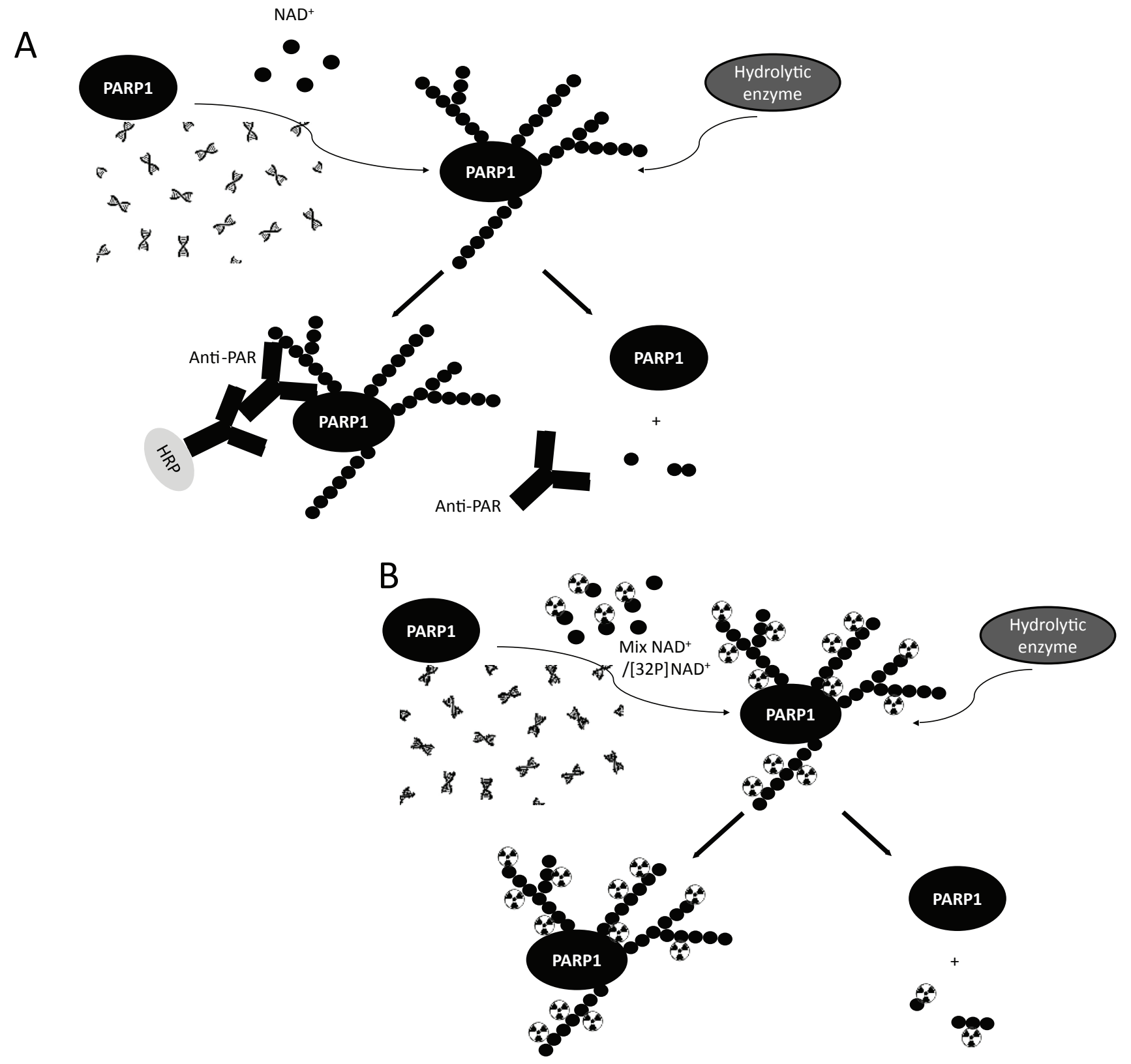


Figure 3

A

Automodified PARP1

CTR NUDT16 PARG

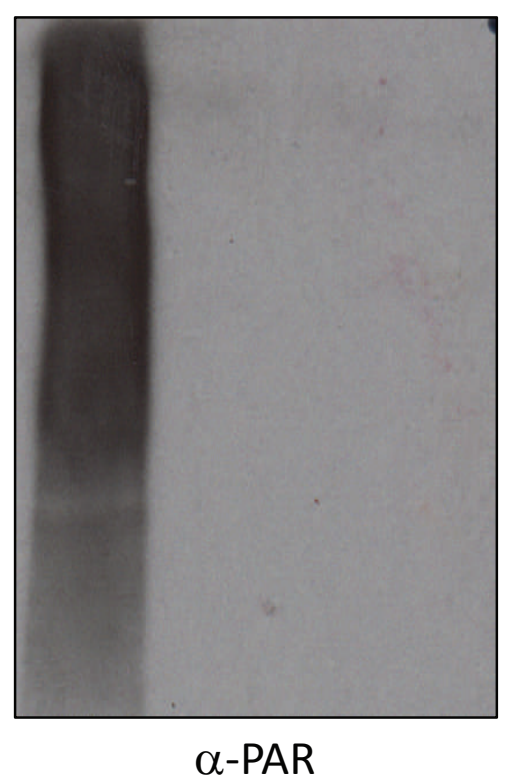

B

Automodified PARP1

CTR NUDT16 PARG MW

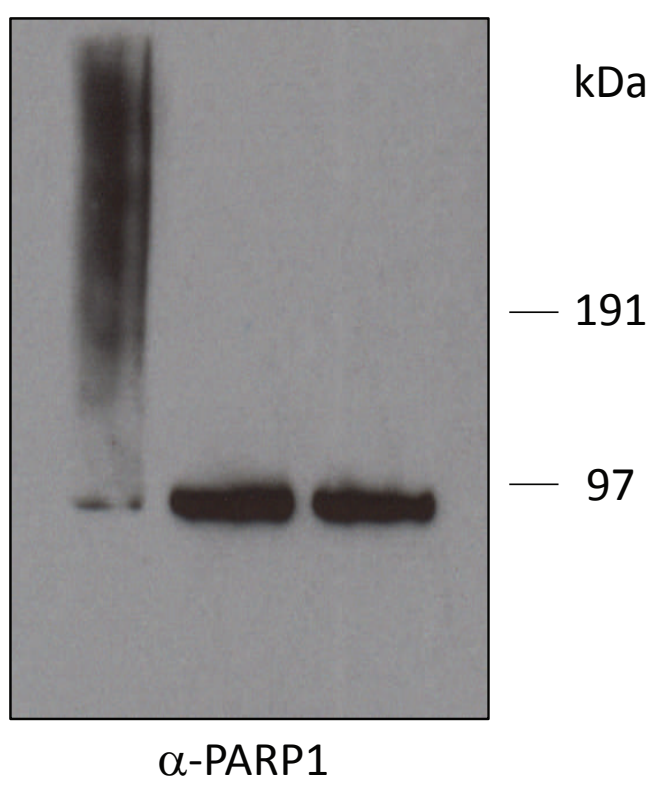




\section{Figure 4}

A

Automodified PARP1

CTR NUDT16 PARG

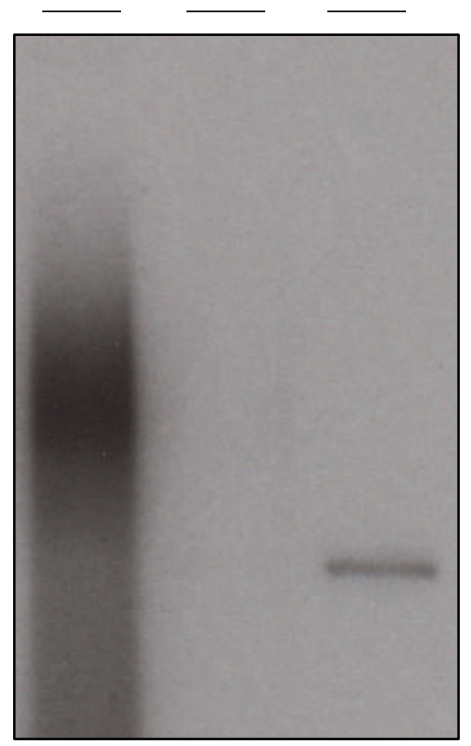

Autoradiography
B

Automodified PARP1

CTR NUDT16 PARG

SDS-PAGE

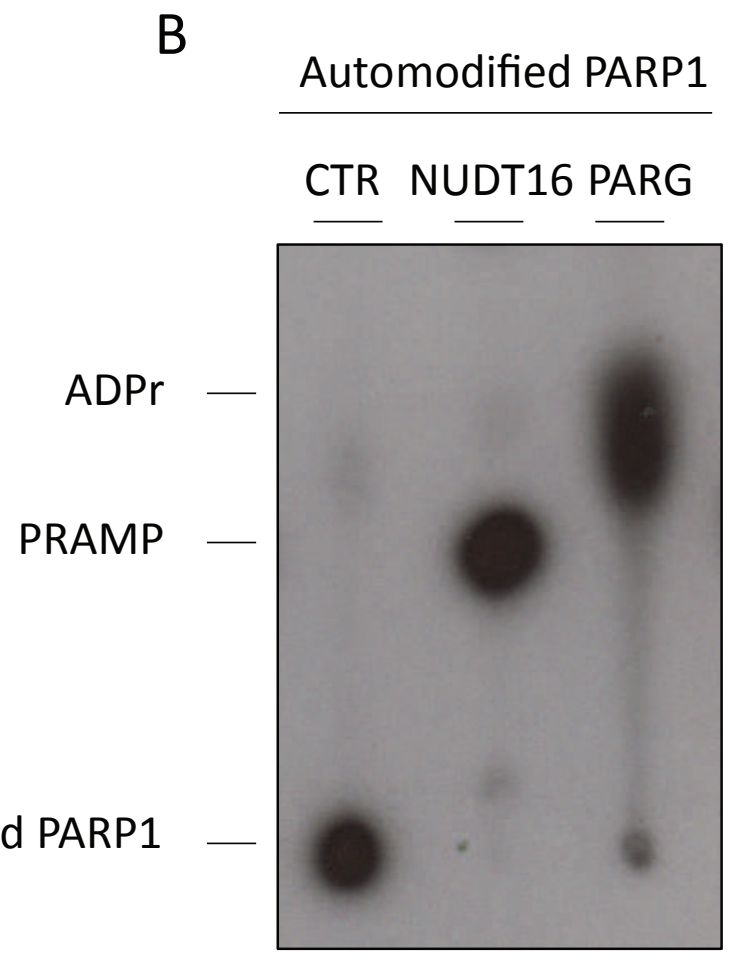

TLC

Autoradiography 
Figure 5

Automodified PARP1-E988Q

CTR TARG1 NUDT16

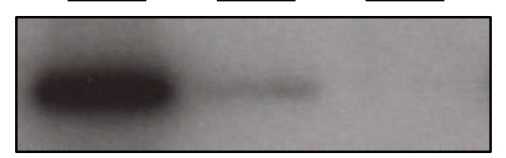

SDS-PAGE

Autoradiography 